\title{
The Effect of Gender and Culture on Loneliness: A Mini Review
}

\author{
Ami Rokach ${ }^{\mathrm{a}, \mathrm{b}}{ }^{\mathrm{*}}$ \\ ${ }^{a}$ Ph. D, Psychology Department, York University, Canada \\ ${ }^{b}$ The Center for Academic Studies, Israel
}

\begin{abstract}
Loneliness is an experience determined by a person's characteristics, her situational variables, gender, and background. This review article describes the myriad of studies, with sometimes contradictory results about the relation of loneliness to gender [with women commonly expressing, though not necessarily experiencing, greater loneliness], and the relation between loneliness and collectivistic and individualistic culture.
\end{abstract}

Keywords:

Gender; Men;

Women; Culture;

Collectivistic; Individualistic.

Article History:

Received: 12 March 2018

Accepted: 29 April 2018

\section{1- Loneliness}

We all yearn to belong. Looking at how animals behave, we realize that we cannot survive, individually, as a community and even as a species without being part of a larger group (Ornish, 1998). When we feel that we do not belong, or actually have no one or group to belong to - we experience the pain of loneliness (Maes, Vanalst, Van den Noortgate \& Goossens, 2017). The 21st century is the age of relationship. Relationships are important, and we believe that we know how to conquer the barriers against closeness that we erect. These days our self-esteem affirmers are intimate and social relations which replaced work that was fulfilling that role just several decades ago. It seems paradoxical whereas on the one hand we yearn and search for closeness and intimate relationships, and on the other hand our social conditions -at least in the Western world- are not conducive to the development of human relations. Our current life style both creates isolation and makes it more difficult to cope with, and while in the past people looked for others to live, work and connect with, these days dating online and the explosive growth of Facebook, are but two attempts at creating virtual communities that may replace, for many, flesh-and-blood friends (Rokach, 2015).

Research revealed that a growing number of people appear to have no one in whom they can confide, resulting in shrinking social ties, that were such an integral part of daily life in past generations (McPherson, Smith-Lovin \& Brashears, 2006). Research has established that In today's fast-paced ever changing world, especially in the Western Hemisphere, when virtual reality replaces the real one for the younger generation, people have no time or energy for establishing a connection with anyone beyond the narrow frame of their own hurried lives, trying to succeed in a culture that rewards nothing but the individual acquisition of power and money (Friedman, 2007; Rokach, 2015).

In general, it is accepted that being alone, feeling alone, perceiving oneself as unloved, unimportant, and uncared for, will result in an experience we entitle 'loneliness'. There are some themes that can be extracted from the various theoretical orientations, and which are characteristic of loneliness experiences:

a. Loneliness is an experience of separation

b. It may arise at birth or in childhood and remain throughout one's life

\footnotetext{
* CONTACT: Arokach@yorku.ca

DOI: http://dx.doi.org/10.28991/esj-2018-01128
}

(C) This is an open access article under the CC-BY license (https://creativecommons.org/licenses/by/4.0/). 
c. It is associated with invalidation of meaning

d. It is difficult to tolerate

e. It motivates humans to seek meaning and connection

f. It may have an evolutionary basis, and

g. It signals the potential for growth and new possibilities.

Based on the various theoretical approaches, and my own research of the past four decades, I see three distinguishing characteristics of all loneliness experiences:

1. Loneliness is a universal phenomenon which is fundamental to being human

2. Although shared by all of us periodically, loneliness is in essence a subjective experience that is influenced by personal and situational variables

3. Loneliness, which is a complex and multifaceted experience, is always very painful, severely distressing and individualistic.

I see loneliness is a "potential" aspect of humans, rather than an undifferentiated aspect of their existence. In other words, to be human is to be able to experience loneliness. I see loneliness as a recessive, a non-dominant trait, which is fully experienced under the "right" conditions. These conditions almost always, include dramatic changes in one's world, such as unfulfilled need for love, belonging or intimacy, estrangement from one's loved ones, country, or children, and a realization of the continuous and never-ending walk along the path that leads to death (Rokach, 2004).

\section{2- The Effects of Loneliness}

Loneliness negatively affects our physical, psychiatric and psychosocial functioning (Cacioppo, Capitanio, \& Cacioppo, \& Cole, 2015). It can bring about, or exacerbate, depression (Hawkley \& Cacioppo, 2010), alcoholism (Akerlind \& Hirnquist, 1992), suicidal ideology (Rudatsikira, Muula, Siziya, \& Twa-Twa, 2007), social anxiety (Kearns, Whitley, Tannahill, \& Ellaway, 2014), and even cognitive decline, the progression of dementia (Wilson et al., 2007), or a recurrent stroke (Cacioppo, Capitanio, \& Cacioppo, \& Cole, 2015). Moreover, physically, it may exacerbate obesity, elevated blood pressure (Hawkley, Masi, Berry, \& Cacioppo, 2006), diminished immunity (Kiecolt-Glaser, Garner, et al., 1984; Pressman et al., 2005), and bring about premature mortality (Holt-Lunstad \& Smith, 2015). No wonder that loneliness has been extensively studied, that the UK has now a minister for addressing loneliness, and that it is recognized as a social epidemic.

\section{3- Gender}

While loneliness is experienced by all who walk on this earth, the literature is unequivocal as to how it is experienced by males and females. Loneliness is expected to be influenced by early life experiences, experiences in adulthood, and by the individual's present situation. Gender needs to be added as a 'master category' to one's social organization, since the process of socialization differs significantly between the genders and thus influence men's and women's loneliness (Nicolaisen \& Thirsen, 2014).

Despite the above, a review of the literature indicated that the association between loneliness and gender is inconclusive. It is quite expected that women, to a larger degree than men, will report that they are lonely (Victor \& Yang, 2012). And indeed, Nolen-Hoeksema and Rusting (2000) observed that women now, in contrast to the past, are more willing to explore, admit, and report feelings like loneliness.

Men are reluctant to disclose experiencing what is socially stigmatized (Borys \& Perlman, 1985). Studies found that when other factors such as marital status, health, age, and living arrangements are controlled, there is no significant gender difference in loneliness experience. However, when loneliness was explored indirectly, it clearly indicated that men were lonelier than women (Aartsen \& Jylhä, 2011). Once again, men's reluctance to admit being lonely is used as an explanation to those conflicting results. "This" Aartsen and Jylhä claimed "was found in all age groups. Men were more socially lonely than women or put differently: it was easier for men to admit to a lack of social contacts than to emotions of missing contact. We found that women were more emotionally lonely than men in the two oldest age groups (50-64 and 65-81), which would be expected since women generally lose their partner earlier than men and live alone for a longer time." (p. 251). Dong and Chen (2017) stated that most of the research suggested that older women were more likely than men to experience loneliness. Pinquart and Sorsen (2001) found that older women experienced more loneliness than older men. They explained it by observing that since women enjoy a longer life than men, they are more prone to remain widowed and thus experience more loneliness. In contrast, other studies found no significant gender differences in loneliness among older adults (Singh \& Misra, 2009; Wilson \& Moulton, 2010), while still others found that loneliness is more prevalent in older men than women (Wang et al., 2011). In participants without a partner, Beutel 
et al. (2017) found, loneliness was more pronounced in women who lived alone and without children. Attempting to explain gender differences, Ang (2016) maintained that women show clear preference for socialization while males who mainly strive for power and rivalry. In accordance with this view, females tend to have more cohesive relationships and closer to their social relationships than males.

\section{4- Culture}

Rook (1984) observed that although shared by all of us periodically, loneliness is in essence a subjective experience that is influenced by personal and situational variables. As such, culture and societal norms surely effect the manner, timing, and experience of loneliness. In this chapter, we will focus on the influence of culture on the experience of loneliness and how we address it. To echo the Basic Behavioural Science Task Force (1996) "Social, cultural, and environmental forces shape who we are and how well we function in the everyday world. The culture we belong to, the neighbourhood we live in, and the demographic composition of our community" (p. 722), all profoundly influence mental health, adjustment to daily demands and our ability to cope with loneliness. McHugh Power et al (2017) observed that attempts to describe loneliness are incomplete without considering the culture that the person lives in. They observed that research has demonstrated that levels of loneliness have been found to differ considerably across cultures.

Triandis (1996) highlighted that we, in the West, tend to view our psychological theories as universal, while they actually are not. Triandis (1996) observed that "the psychology of the individualistic cultures of the West differ to some extent from the psychology of the collectivist cultures of the East and the traditional cultures of Africa and Latin America" (p.408). In agreement with Triandis' assertion, researchers must take cultural and ethnic differences into account when designing research if we are to truly understand the commonality and difference between people (Doherty, Hatfield, Thompson \& Choo, 1994; Shweder \& Sullivan, 1993; see also Rokach, Bacanli \& Ramberan, 2000).

The earliest reference to loneliness, In Christian and Jewish cultures, had been also the first thing God had regarded as 'not good', after which followed the creation of Eve (in van Staden \& Coetzee, 2010). Aristotle, the Greek philosopher highlighted that point and declared that "he who is unable to mingle in society, or who requires nothing, by reason of sufficing for himself, is no part of the state, so that he is either a wild beast or a divinity" (van Staden \& Coetzee, 2010; 2004; p. 9).

Hansen and Slagsvold (2016) explored difference in late-life loneliness as related to the European country of residence of their research participants. They reported that the rate of severe loneliness is 30-55\% among men and women in Eastern Europe, compared with 10-20\% among their peers in Western and Northern Europe. The researchers concluded that cultural differences cultural may account for some of the unexplained country variance in loneliness. "In familistic cultures" they concluded "people tend to emphasize and expect strong ties within the family and community. Such cultures may prevent loneliness by promoting social integration (p. 446)." However, those very same high expectations may increase feelings of loneliness if those expectations are not met. Northern Europe is characterized by weak family and community ties while the Mediterranean and Eastern European countries endorse and promote strong ties (Hansen \& Slagsvold, 2016). Individualistic values tend to dominate in "weak family" areas, whereas "strong family" dominates collectivistic cultures. Individualistic cultures tend to be characterized by increasing proportions of people living alone, increased divorce rates, and declining family size and that of kinship networks. Unsurprisingly, stereotypes support the view that individualism and de-familialism of Northern Europe are correlated with high levels of social isolation and loneliness (Dykstra 2009).

It is therefore suggested that loneliness may differ according to the manner in which cultures influence expectations of social connectedness (see also Fokkema, de Jong Gierveld \& Dykstra 2012). Further "the relationships between social context and loneliness seem to vary cross-culturally. High prevalence of living alone appears to be related to less loneliness across European countries, moving from north to south.... This is thought to be due to the differing expectations common to northern and southern countries: in southern countries, it is relatively uncommon to live alone, while in more northern countries it is more common. Older adults who are living alone in Northern countries are living in a manner which is concordant with their expectations, while those living alone in southern countries are living in a manner discordant to their expectations (of living with others), and loneliness arises as a result" (Hansen \& Slagsvold, 2016; p.395).

There are several factors related to loneliness and culture, such as power distance, uncertainty avoidance, individualism/collectivism, masculinity/femininity, and long-term orientation (Hofstede, 2001). The dimension of individualism emerged as the most dominant in the cross-cultural literature (e.g., Oyserman, Coon, \& Kemmelmeier, 2002). According to Hofstede (2001), individualism is characterized by valuing and striving for autonomy and placing one's personal goals above those of others. Collectivism, on the other hand, sees the interests of one's group, such as one's family or community, as more important than those of oneself. In that respect, Anderson (1999) assessed how Chinese people experience loneliness. The Chinese feel lonelier than Americans, and tend to blame themselves if they felt their social network was lacking, attributing that lack to their inability to create a solid supportive social network. Americans, being used to direct their attention to themselves and their own personal development, were interestingly 
less likely to see themselves as responsible for their loneliness, but instead, blamed external factors if their social network fell short of what they desired. Indeed, studies that compared individualistic and collectivistic cultures generally indicated that residents of collectivistic societies are more likely to feel lonely than those in individualistic societies in spite of the fact that individuals are more likely to live alone in the latter. Research by Lykes and Kemmelmeier (2014) found that: older adults in collectivistic cultures are lonelier than older adults in individualistic cultures. Additionally, culture moderates the influence of the frequency of contact with family and friends on loneliness. It was discovered that friends and family are of utmost importance in moderating loneliness in collectivistic cultures, and when they are missing, loneliness is experienced. In individualistic cultures, on the other hand, that support is not as salient, and may thus be less expected.

In African cultures, for example, loneliness is much about lack of social interconnectedness as these concepts are central in the everyday thinking and doing of many African cultures in particular concerning the ways in which people experience relationships and loneliness (van Staden \& Coetzee, 2010). In the Japanese culture, loneliness is experienced within interconnectedness, where even the most desperate ones, contemplating suicide, seek others who are as suicidal as they are, so that they feel that they do not die alone (Ozawa-de Silva, 2008). Exploring differences in loneliness between North American and European people by focusing on the Spaniards, they apparently scored lower on all of Rokach's (2008) six coping strategies. Checking the manner in which Canadian, South Asian, and West Indian cope with loneliness, again Rokach (1999) found significant differences stemming from the meaning that loneliness has in those cultures.

In conclusion, it may be said that in individualistic cultures loneliness is more about personal romantic expectations, whereas in collectivistic cultures loneliness is more about social approval (Yum, 2003). It means that efforts to help cope with loneliness, must take into consideration one's gender and especially the culture in which that person lives and operates.

\section{5- References}

[1] Aartsen, M., \& Jylhä, M. (2011). Onset of loneliness in older adults: Results of a 28 year prospective study. European Journal of Ageing, 8(1), 31-38. doi: 10.1007/s10433-011-0175-7

[2] Akerlind, I., \& Hörnquist, J. O. (1992). Loneliness and alcohol abuse: A review of evidences of an interplay. Social Science \& Medicine, 34, 405-414. doi:10.1016/0277-9536(92)90300-F

[3] Anderson, C. A. (1999). Attributional style, depression, and loneliness: A cross-cultural comparison of American and Chinese students. Personality and Social Psychology Bulletin, 25, 482-499. doi:10.1177/0146167299025004007

[4] Ang, C.S. (2016). Types of social connectedness and loneliness: The joint moderating effects of age and gender. Applied Research Quality Life, 11, 1173-1187. DOI 10.1007/s11482-015-9428-5

[5] Basic Behavioural Science Task Force of the National Advisory Mental Health Council (1996). Basic behavioural science research for mental health: Social cultural and environmental processes. American Psychologist, 51(7), 722-731.

[6] Beutel, M.E., Klein, E.M., Brähler, E, Reiner, I., Jünger, C., Michal, M., Wiltink, J., Wild, P.S. Münzel, T.M., Lackner, K.J. \& Tibubos, A.N. (2017). Loneliness in the general population: prevalence, determinants and relations to mental health. BMC Psychiatry, 17:97. DOI 10.1186/s12888-017-1262-x

[7] Borys, S., \& Perlman, D. (1985). Gender differences in loneliness. Personality and Social Psychology Bulletin, 11, 63-74.

[8] Cacioppo, J. T., Cacioppo, S., Capitanio, J. P., \& Cole, S. W. (2015). The neuroendocrinology of social isolation. Annual Review of Psychology, 66, 733-767. doi:10.1146/annurevpsych-010814-015240

[9] Cacioppo, J. T., Fowler, J. H., \& Christakis, N. A. (2009). Alone in the crowd: The structure and spread of loneliness in a large social network. Journal of Personality and Social Psychology, 97, 977-991.

[10] Doherty, R.W., Hatfield, E., Thompson, K., \& Choo, R. (1994). Cultural and ethnic influences on love and attachment: Brief Report. Personal Relationships, 1, 391-398.

[11] Dong, X \& Chen, R. (2017). Gender differences in the experience of loneliness in U.S. Chinese older adults. Journal of Women \& Aging 29(2), 115-125. http://dx.doi.org/10.1080/08952841.2015.1080534

[12] Dong, XQ, Chang, E-S, Wong, E. \& Simon, M. (2012). Perception and negative effect of loneliness in a Chicago Chinese population of older adults. Archives of Gerontology and Geriatrics, 54, 151-159. doi:10.1016/j.archger.2011.04.022

[13] Dykstra, P. A. (2009). Older adult loneliness: Myths and realities. European Journal of Ageing, 6(2), 91-100.

[14] Fokkema, T., de Jong Gierveld, J. \& Dykstra, P.A. (2012). Cross-national differences in older adult loneliness. The Journal of Psychology: Interdisciplinary and Applied, 146 (1-2), 201-228.

[15] Friedman, R. L. (2007). Widening the therapeutic lens: Sense of belonging as an integral dimension of the human experience. 
A Dissertation submitted to the Wright Institute Graduate School.

[16] Hansen, T. \& Slagsvold, B. (2016). Late-life loneliness in 11 European countries: Results from the generations and gender survey. Social Indicator Research, 129, 445-464. DOI 10.1007/s11205-015-1111-6.

[17] Hawkley, L. C., \& Cacioppo, J. T. (2010). Loneliness matters: A theoretical and empirical review of consequences and mechanisms. Annals of Behavioural Medicine, 40, 218-227. doi: 10.1007/s12160-010-9210-8

[18] Hawkley, L. C., Masi, C. M., Berry, J. D., \& Cacioppo, J. T. (2006). Loneliness is a unique predictor of age-related differences in systolic blood pressure. Psychology and Aging, 21, 152-164. doi:10.1037/0882-7974.21.1.152

[19] Hofstede, G. (2001). Culture's consequences: Comparing values, behaviors, institutions, and organizations across nations. Thousand Oaks, CA: Sage.

[20] Holt-Lunstad, J., \& Smith, T. B. (2015). Loneliness and social isolation as risk factors for mortality: A meta-analytic review. Perspectives on Psychological Science, 10, 227-237.

[21] Kearns, A., Whitley, E., Tannahill, C., \& Ellaway, A. (2014). Loneliness, social relations and health and well-being in deprived communities. Psychology, Health \& Medicine, 1-13. doi:10.1080/13548506.2014.940354

[22] Kiecolt-Glaser, J. K., Garner, W., Speicher, C. E., Penn, G. M., Holliday, J. E., \& Glaser, R. (1984). Psychosocial modifiers of immunocompetence in medical students. Psychosomatic Medicine, 46, 7-14. doi:10.1097/00006842-198401000-00003

[23] Lykes, V.A. \& Kemmelmeier, M. (2014). What Predicts Loneliness? Cultural Difference Between Individualistic and Collectivistic Societies in Europe. Journal of Cross-Cultural Psychology, 45(3) 468-490. DOI: 10.1177/0022022113509881

[24] Maes, M., Vanalst, J., Van den Noortgate, Goossens, L. (2017). Intimate and Relational Loneliness in Adolescence. Journal Child Family Studies, 26, 2059-2069. DOI 10.1007/s10826-017-0722-8

[25] McHugh Power, J.E., Hannigana, C., Carneya, S. \& Lawlor, B.A. (2017). Exploring the meaning of loneliness among socially isolated older adults in rural Ireland: a qualitative investigation. Qualitative Research in Psychology, 14(4), $394-414$. https://doi.org/10.1080/14780887.2017.1329363

[26] McPherson, M., Smith-Lovin, L., \& Brashears, M. E. (2006). Social Isolation in America: Changes in Core Discussion Networks Over Two Decades. American Sociological Review, 71(3), 353-375.

[27] Nicolaisen, M. \& Thorsen, K. (2014). Who are lonely? Loneliness in different age groups (18-81), using two measures of loneliness. International Journal of Aging and Human Development, 78(3) 229-257.

[28] Nolen-Hoeksema, S., \& Rusting, C.L. (2000). Gender differences in well-being. In D. Kahneman, E. Diener \& N. Schwartz (Eds.), Well-being: The foundations of hedonic psychology. New York, NY: Russell Sage Foundation.

[29] Ornish, D. (1998). Love and Survival: The scientific basis for the healing power of intimacy. New York: HarperCollins.

[30] Oyserman, D., Coon, H. M., \& Kemmelmeier, M. (2002). Rethinking individualism and collectivism: Evaluation of theoretical assumptions and meta-analyses. Psychological Bulletin, 128, 3-72.

[31] Pinquart, M., \& Sorensen, S. (2001). Influences on loneliness in older adults: A meta-analysis. Basic and Applied Social Psychology, 23(4), 245-266. doi:10.1207/S15324834BASP2304_2

[32] Prince, M. J., Harwood, R. H., Blizard, R. A., Thomas, A., \& Mann, A. H. (1997). Social support deficits, loneliness and life events as risk factors for depression in old age. The Gospel Oak Project VI. Psychological Medicine, 27(2), $323-332$. doi:10.1017/S0033291796004485

[33] Pressman, S. D., Cohen, S., Miller, G. E., Barkin, A., Rabin, B. S., \& Treanor, J. J. (2005). Loneliness, social network size, and immune response to influenza vaccination in college freshmen. Health Psychology, 24, 297-306. doi:10.1037/02786133.24.3.297

[34] Rokach, A. (1999). Cultural background and coping with loneliness. Journal of Psychology, 133(2), 217-229.

[35] Rokach, A. (2004). Loneliness then and now: Reflections on social and emotional alienation in everyday life. Current Psychology, 23(1), 24-40.

[36] Rokach, A. (2008). Coping with loneliness in North America and Spain. Psychology Journal, 5(1), 51-68.

[37] Rokach, A. (2015). Loneliness, alienation, solitude and our lives. In A. Sha'ked \& A. Rokach (Ed.) Addressing loneliness: Coping, prevention and clinical interventions (Pp. 3-19). NY: Routledge.

[38] Rokach, A., Bacanli, H. \& Ramberan, G. (2000). Coping with loneliness: A cross- cultural comparison. European Psychologist, 5(4), 302-311.

[39] Rook, K. S. (1984). Research on social support, loneliness, and social isolation: Toward an integration. In P. Shaver (Ed.), 
Review of Personality and Social Psychology: Emotions, Relationships, and Health (Vol. 5, pp. 239-264). Beverly Hills, CA: Sage.

[40] Rudatsikira, E., Muula, A. S., Siziya, S., \& Twa-Twa, J. (2007). Suicidal ideation and associated factors among school-going adolescents in rural Uganda. BMC Psychiatry, 7, Article 67. Sciences, 3(1), 1-29.

[41] Shweder, R.A., \& Sullivan, M.A. (1993). Cultural psychology: Who needs it? Annual Review of Psychology, 44, 497-523.

[42] Singh, A., \& Misra, N. (2009). Loneliness, depression and sociability in old age. Industrial Psychiatry Journal, 18(1), 51-55. doi:10.4103/0972-6748.57861

[43] Triandis, H.C. (1996). The psychological measurement of cultural syndromes. American Psychologist, 51(4), 407-415.

[44] Wang, G., Zhang, X., \& Wang, K., Li, Y., Shen, Q., Ge, X., \& Hang, W. (2011). Loneliness among the rural older people in Anhui, China: Prevalence and associated factors. International Journal of Geriatric Psychiatry, 26(11), 1162-1168.

[45] Wilson, R. S., Krueger, K. R., Arnold, S. E., Schneider, J. A., Kelly, J. F., Barnes, L. L., . . Bennett,

[46] D. A. (2007). Loneliness and risk of Alzheimer disease. Archives of General Psychiatry, 64, 234-240. doi:10.1001/archpsyc.64.2.234

[47] Wilson, C., \& Moulton, B. (2010). Loneliness among older adults: A national survey of adults 45+. Washington, DC: AARP.

[48] Van Staden, C.W. \& Coetzee, K. (2010). Conceptual relations between loneliness and culture.

[49] Victor, C. R., \& Yang, K. (2012). The prevalence of loneliness among adults: A case study of the United Kingdom. The Journal of Psychology, 146(1-2), 85-104.

[50] Yum, Y.O. (2003). The relationships among loneliness, self/partner constructive maintenance behaviour, and relational satisfaction in two cultures. Community Studies, 54, 451-467. 